\title{
The AMTEX Partnership ${ }^{\text {тм }}$
}
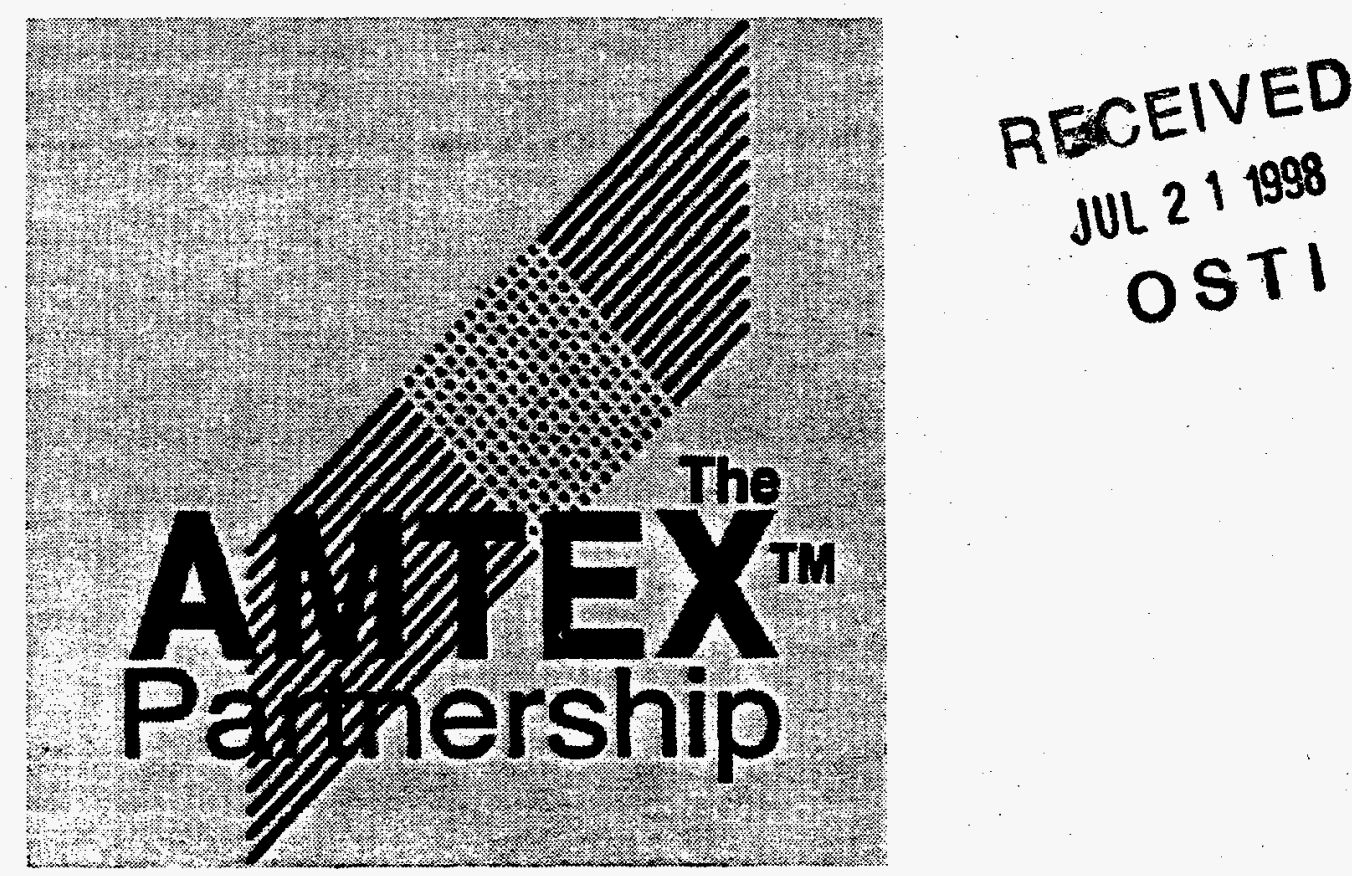

DISTRIBUTION OF THIS DOCLMENT IS UAKMITED

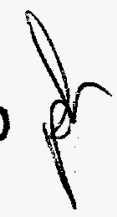

MASTER

March 1997 


\section{DISCLAIMER}

This report was prepared as an account of work sponsored by an agency of the United States Government. Neither the United States Government nor any agency thereof, nor any of their employees, makes any warranty, express or implied, or assumes any legal responsibility for the accuracy, completeness, or usefulness of any information, apparatus, product, or process disclosed, or represents that its use would not infringe privately owned rights. Reference herein to trademark, manufacturer, or otherwise, does not necessarily constitute or imply its endorsement, recommendation, or favoring by the United States Government or any agency thereof. The views and opinions expressed herein do not necessarily state or reflect those of the United States Government or any agency thereof.

Prepared by the

Oak Ridge Y-12 Plant

managed by

LOCKHEED MARTIN ENERGY SYSTEM, INC.

for the

U. S. DEPARTMENT OF ENERGY

under contract DE-AC05-84-OR21400 


\section{DISCLAIMER}

Portions of this document may be illegible in electronic image products. Images are produced from the best available original document. 


\title{
The AMTEX Partnership ${ }^{\text {TM }}$
}

\author{
Mid Year Report \\ Fiscal Year 1997
}

March 1997

\author{
Issued by \\ The AMTEX Program Office \\ Mark A. Miller, Manager \\ AMTEX Laboratory Program \\ and
}

Richard K. Quisenberry, Executive Director

AMTEX Industry Program 



\section{CONTENTS}

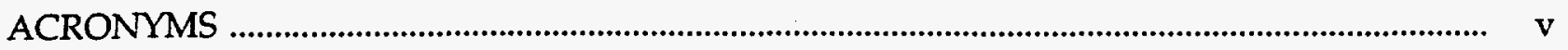

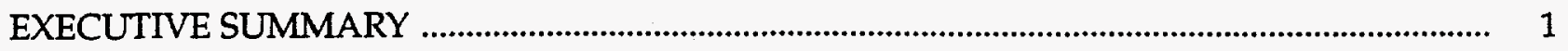

OPERATIONS AND PROGRAM MANAGEMENT ........................................................................ 7

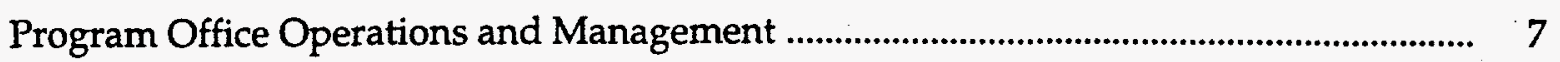

Operating Committee Activities and Actions .................................................................... 7

Industry Technical Advisory Committee .............................................................................. 8

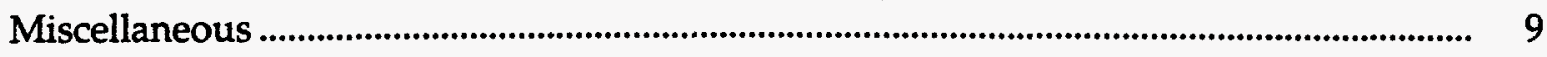

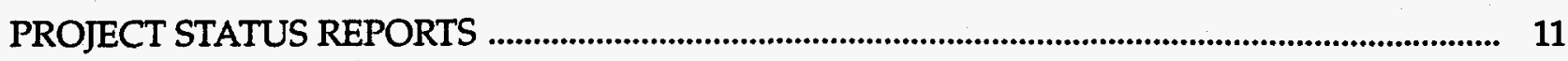

Computer-Aided Fabric Evaluation ................................................................................. 11

Demand Activated Manufacturing Architecture .............................................................. 13

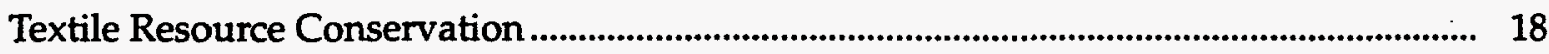

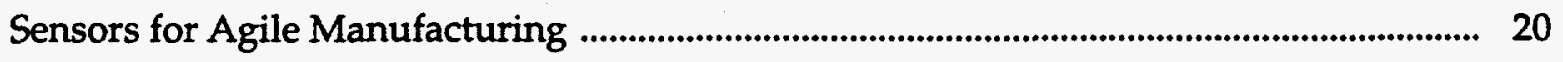

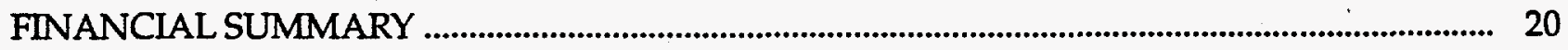

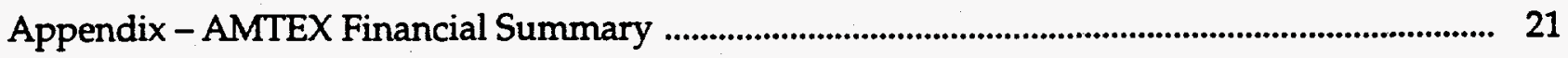




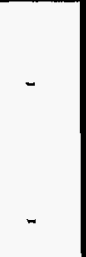




\section{ACRONYMS}

AAMA

ARMS

ATMI

C\&I

CAD

CAFE

CBM

CPPG

CRADA

DAMA

DAME

DOE

DOE/ER

DP

EDI

EE

EM

EO\&C

EPA

ER

GUI

IBM

ITAC

ITC

ITI

ITT

KTA

LANL

LLNL

NCSU

NSDB

NTC

ORNL

PMD

PNNL

R\&D

SCIP

SNL

TAC

[TC]

TReC

USL

VICS

WWW
American Apparel Manufacturers Association

Apparel Retail Modeling System

American Textile Manufacturer's Institute

Connectivity and Infrastructure

Computer-Aided Design

Computer-Aided Fabric Evaluation

Cooperative Business Management

Color Printed Pattern Goods

Cooperative Research and Development Agreement

Demand Activated Manufacturing Architecture

Data Analysis and Modeling Environment

Department of Energy

DOE Energy Research

Defense Programs

Electronic Data Interchange

Energy Efficiency

Environmental Management

Education, Outreach, and Communication

Environmental Protection Agency

Energy Research

Graphical User Interface

International Business Machines

Industry Technical Advisory Committee

Integrated Textile Complex

Internet Tradeline, Inc.

Institute of Textile Technology

Knitted Textile Association

Los Alamos National Laboratory

Lawrence Livermore National Laboratory

North Carolina State University

National Sourcing Database

National Textile Center

Oak Ridge National Laboratory

Pick Measurement Device

Pacific Northwest National Laboratory

Research and Development

Supply Chain Integration Program

Sandia National Laboratories

Technical Advisory Committee

Textile Clothing Technology Corporation

Textile Resource Conservation

University of Southwestern Louisiana

Voluntary Interindustry Communications Standard World Wide Web 


\section{EXECUTIVE SUMMARY}

The AMTEX Partnership ${ }^{\top \mu}$ is a collaborative research and development program among the U.S. Integrated Textile Complex (ITC), the U.S. Department of Energy (DOE), the DOE national laboratories, other federal agencies and laboratories, and universities. The goal of AMTEX is to strengthen the competitiveness of this vital industry, thereby preserving and creating U.S. jobs.

\section{Operations and Program Management}

The operations and program management of the AMTEX Partnership is provided by the Program Office. The Office produces this report semiannually to provide information on the progress, operations and program management of the partnership.

- Changes in the AMTEX Laboratory Office were made this year as a result of the funding situation for FY 1997. DOE Defense Programs is the only funding source for FY 1997, contributing \$10M. DOE Energy Research is not contributing funds to AMTEX this year.

The Laboratory Program Office was moved from the Pacific Northwest National Laboratory (PNNL) to the Y-12 Plant in Oak Ridge. Dr. Mark Miller has assumed laboratory program management duties replacing Dr. Doug Lemon. The industry liaison office at Milliken and Company has increased its support for the program office in partial compensation for funding reductions to the laboratory program office.

Three AMTEX projects funded in FY 1997 are Diamond Activated Manufacturing Architecture (DAMA), Computer-Aided Fabric Evaluation (CAFE), and Textile Resource Conservation (TReC). The five sites involved in AMTEX work are Sandia National Laboratory (SNL), Los Alamos National Laboratory (LANL), Lawrence Livermore National Laboratory (LLNL), the Oak Ridge Y-12 Plant, and the Oak Ridge National Laboratory (ORNL) (the latter is funded through Y-12).

The AMTEX Operating Committee met in Charlotte, North Carolina, on December 18, 1996. Dr. Richard Quisenberry, Executive Director, talked about the current status of the partnership mentioning that intellectual property is being transferred, hardware and software are being transferred, and deliverables are pretty much on schedule. A discussion was held on promoting partnerships in general and using the AMTEX principles as the example of how a partnership should be constructed.

Dr. Quisenberry stated that the goal for FY 1998 is to restore the full research and development (R\&D) agenda for AMTEX, to engage the entire range of the ITC, involve multiple DOE Offices [Energy Research (ER) and Environmental Management (EM) as well as the Defense Programs (DP)], and attract other government laboratories such as the Environmental Protection Agency. Industry project directors presented the status of their projects with emphasis on work to be conducted in FY 1997.

The Industry Technical Advisory Committee met in Raleigh, North Carolina, on February 25, 1997. Dr. Quisenberry noted that the FY 1998 budget submitted by the 
President to Congress included $\$ 5.5 \mathrm{M}$ from DOE/DP. DOE/ER is expected to contribute $\$ 3.5 \mathrm{M}$. There is the possibility of an increase in the DP portion to $\$ 10 \mathrm{M}$.

Dr. Quisenberry responded to a request from a Senate subcommittee for a four-year AMTEX budget. His submission shows \$13.5M in FY 1998, \$17M in FY 1999 and FY 2000, and \$11M for FY 2001, with funds from both DP and ER each year.

On the subject of industry membership it was noted that a number of partners were lost from FY 1996 to FY 1997. Reasons for losing participation include the annual funding uncertainties, suspended projects and tasks, and a perceived lack of commercial results. Despite these problems, industry contributions continue to be greater than government contributions to the partnership.

Industry project directors gave presentations on the status of their projects. General observation on the AMTEX R\&D efforts included the difficulty in turning generic, process-related R\&D into real products; focusing on a few tasks of the project that can be completed; the ability to capitalize creation of products, which is as important as technical expertise; moving tasks from one laboratory to another, which is almost impossible now; and industry must continually review and update project goals and specifications for hardware and software.

\section{Project Status}

\section{Computer-Aided Fabric Evaluation}

Commercialization of CAFE technologies is the major thrust of the FY 1997 work. Vendors are working with the national laboratory researchers to define specifications for hardware and software for commercial products that implement greige weave/ knit and color printed pattern inspection systems. A preliminary economic analysis of the greige inspection systems has been prepared by the vendor.

Two test units of the SNL greige weave sensor system have operated for several months at industry sites. The false alarm rate has been reduced to acceptable levels. Full-width pick defect detection has achieved an acceptable rate. Work has concentrated on warp defect detection where the rate is still below acceptable levels. A more detailed definition of warp defect detection requirements and a test plan are being generated. The knit inspection system leverages heavily off the weave system and delivery of a prototype this fiscal year is on schedule.

Work on the pick measurement device has been reduced in scope because of funding limitations. A beta test device performed within specifications for the pick density on plain weave and twill fabrics. Modifications have been made to address problems with other fabric types. Delivery of the next generation device to the vendor is scheduled for July 1997.

Additional work on the machine diagnostics system has not been funded for FY 1997. Project participants have been urged to pursue separate industry/laboratory arrangements outside CAFE to put this technology to use. 
Agreements have been signed with two vendors who will team to commercialize the color printed pattern inspection system. Fieldcrest Cannon has been selected as the beta system test site. A pre-beta field test was conducted during March to collect data during normal production operations and test several subsystems that will be part of the beta unit. Preliminary work is being done to determine feasibility and requirements for performing data collection during the printing process of knit greige goods.

\section{Demand Activated Manufacturing Architecture}

The DAMA project became the first AMTEX project to execute a multi-laboratory cooperative research and development agreement (CRADA) to document the scope of work and funding of the participating laboratories and industry partners. Signatures of seven laboratories and Textile Clothing Technology Corporation [TC] $]^{2}$ were obtained on March 24, 1997.

A dynamic simulation code, "Extend," has been chosen for prototype simulation model development for in-depth (phase II) analyses of product pipelines investigated in previous years. The nylon jacket pipeline analysis has proceeded through definition of requirements, activity-based representation of the pipeline, creation of data templates, and initial construction of the apparel manufacturing model. The team anticipates approximately 200 process steps will be included overall.

The team for the bedsheet pipeline has not been defined after one industry participant from the original analysis did not renew AMTEX membership. A third pipeline analysis, originally to be a new product line, has been changed to a simulation of the men's cotton slacks pipeline. The analysis will use the same tools and methodology as the nylon jacket analysis but will not go into the same depth to allow demonstrations at an earlier date.

The first TEXNET pilot was initiated among Milliken, Warren Featherbone, and Mercantile on February 3, sharing seven categories and four formats of information. A second pilot among L. L. Bean, Cone Mills, and Thomas Bradford (the latter not a DAMA member) is on schedule to begin in June. A major upgrade to TEXNET has been issued. The TReC project is investigating the use of TEXNET as the architecture for sharing environmental data, and a third pilot could be implemented this year.

Software agreements between [TC] $]^{2}$ and International Business Machine (IBM) allow the use of IBM-developed tools as part of the Supply Chain Integration Program (SCIP). SCIP has also been updated to improve the user interface, scheduling routines, and accommodate multiple manufacturing stages.

The Data Analysis and Modeling Environment (DAME) apparel module has been restructured in cooperation with the American Apparel Manufacturers Association (AAMA). Preliminary work on the textile module is underway. Two Voluntary Interindustry Communications Standard (VICS) committees have agreed to support the effort to model activities in their areas of interest. A prototype of the new DAME web presentation and a SCIP demonstration have been installed on the CBM home page. 
DAMA exhibited at the Bobbin Show and the American Textile Manufacturing Institute (ATMI) conference. A poster session was presented at the National Textile Center (NTC) Forum. Presentations were made at the AAMA Technical Advisory Committee (TAC), the Knitted Textile Association (KTA) annual meeting, and the Council of Logistics Management meeting. Vendors have been recommended for commercialization of TEXNET and the National Sourcing Database, respectively, IBM and Internet Tradeline, Inc., who have become affiliate members of the project.

A technical peer review of the project was held in December 1996 with review team members from LANL, PNNL, SNL, ORNL, Georgia Tech, and Burlington. The team noted that the national laboratory staff has demonstrated good technical performance and the degree of interaction among tasks is appropriate. Suggestions included emphasis on completion of software tools in the near term and establishment of more joint efforts with industry.

\section{Textile Resource Conservation}

The $\mathrm{TReC}$ project has undergone another reduction in scope with the absence of DOE/ER funding. Three tasks are being worked in FY 1997, one at each of the DP laboratories: LANL, SNL, and LLNL. The laboratory project manager position is vacant this year.

The CRADA for the emissions monitoring task at LANL was canceled at the end of FY 1996. The field apparatus built last year was disassembled and stored. In March 1997, a new CRADA was signed allowing work to begin. The prototype has been cleaned, reassembled, calibrated, and diagnostic tests run. A student research assistant has been recruited to help in the project.

The environmental decision tools task at SNL began work in January after an amendment to the existing CRADA to extend the performance period through FY 1997 was signed. Discussions were held among industry and laboratory personnel on hardware and software requirements for sharing of environmental data. The preferred option is to use the TEXNET architecture developed by the DAMA project, with the contingency of using a PC-based system if necessary. Further discussions on the types and end uses of data have allowed preliminary work on data structures and templates to begin.

The enhanced washing task at LLNL has developed a promising technology for reducing the amount of water used in the textile industry. Improvements have been made to the continuous washing apparatus constructed in FY 1996 with the use of new materials. Experimental results of tint removal from cotton twill fabric have resulted in equivalent cleaning with less than one-third the water use through this technology. Tests of caustic removal were not as promising, with a 30 percent improvement in removal from cotton, and essentially no improvement with pure polyester. Tests of chlorine and dye removal are planned as well as mechanical enhancements to the system. 
AMTEX FY 1997 Financial Summary (\$K)

As of $3 / 31 / 97$ ( $50 \%$ of FY)

\begin{tabular}{|c|c|c|c|c|c|c|c|c|}
\hline $\begin{array}{l}\text { Project } \\
\text { Lab Ca }\end{array}$ & $\begin{array}{c}\text { FY96 } \\
\text { Carryover }\end{array}$ & $\begin{array}{l}\text { FY97 } \\
\text { Budget }\end{array}$ & $\begin{array}{c}\text { Total } \\
\text { Budget }\end{array}$ & $\begin{array}{c}\text { 1st Qtr } \\
\text { Cost }\end{array}$ & $\begin{array}{c}\text { 2nd Qtr } \\
\text { Cost }\end{array}$ & $\begin{array}{l}\text { Total } \\
\text { Cost }\end{array}$ & Percent & $\begin{array}{l}\text { Budget } \\
\text { Balance }\end{array}$ \\
\hline \multicolumn{9}{|l|}{ DAMA } \\
\hline SNL & 334 & 2,660 & 2,994 & 573 & 721 & 1,294 & 43 & 1,700 \\
\hline LANL & 1 & 1,380 & 1,381 & 214 & 431 & 645 & 47 & 736 \\
\hline LLNL & 21 & 2,010 & 2,031 & 435 & 568 & 1,003 & 49 & 1,028 \\
\hline OR/Y12 & 120 & 300 & 300 & 78 & 45 & 123 & 41 & 177 \\
\hline Total & 356 & 6,350 & 6,706 & 1,300 & 1,765 & 3,065 & 46 & 3,641 \\
\hline \multicolumn{9}{|l|}{ CAFE } \\
\hline SNL & 99 & 1,984 & 2,083 & 266 & 591 & 857 & 41 & 1,226 \\
\hline OR/Y12 & 74 & 486 & 560 & 184 & 173 & 357 & 64 & 203 \\
\hline LLNL & -2 & 30 & 28 & 23 & 11 & 34 & 121 & -6 \\
\hline Total & 171 & 2,500 & 2,671 & 473 & 775 & 1,248 & 47 & 1,423 \\
\hline \multicolumn{9}{|l|}{$\mathrm{TReC}$} \\
\hline SNL & 29 & 200 & 229 & 3 & 29 & 32 & 14 & 197 \\
\hline LANL & 0 & 250 & 250 & 0 & 58 & 58 & 23 & 192 \\
\hline LLNL & -12 & 450 & 438 & 43 & 60 & 103 & 24 & 335 \\
\hline Total & 17 & 900 & 917 & 46 & 147 & 193 & 21 & 724 \\
\hline \multicolumn{9}{|c|}{ Program Office } \\
\hline OR/Y12 & 120 & 250 & 250 & 43 & 59 & 102 & 41 & 148 \\
\hline Total & 544 & 10,000 & 10,544 & 1,862 & 2,746 & 4,608 & 44 & 5,936 \\
\hline \multicolumn{9}{|c|}{ Summary by Project (\$K) } \\
\hline DAMA & 356 & 6,350 & 6,706 & 1,300 & 1,765 & 3,065 & 46 & 3,641 \\
\hline CAFE & 171 & 2,500 & 2,671 & 473 & 775 & 1,248 & 47 & 1,423 \\
\hline $\mathrm{TReC}$ & 17 & 900 & 917 & 46 & 147 & 193 & 21 & 724 \\
\hline $\begin{array}{l}\text { Program } \\
\text { Office }\end{array}$ & 0 & 250 & 250 & 43 & 59 & 102 & 41 & 148 \\
\hline Total & 544 & 10,000 & 10,544 & 1,862 & 2,746 & 4,608 & 44 & 5,936 \\
\hline \multicolumn{9}{|c|}{ Summary by Laboratory (\$K) } \\
\hline SNL* & 462 & 4,844 & 5,306 & 842 & 1,341 & 2,183 & 41 & 3,123 \\
\hline LLNL & 7 & 2,490 & 2,497 & 501 & 639 & 1,140 & 46 & 1,357 \\
\hline LANL & 1 & 1,630 & 1,631 & 214 & 489 & 703 & 43 & 928 \\
\hline OR/Y12 & 74 & 1,036 & 1,110 & 305 & 277 & 582 & 52 & 528 \\
\hline Total & 544 & 10,000 & 10,544 & 1,862 & 2,746 & 4,608 & 44 & 5,936 \\
\hline
\end{tabular}

- Does not include \$26K carryover for Sensors project. 


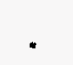




\section{OPERATIONS AND PROGRAM MANAGEMENT}

\section{Program Office Operations and Management}

Changes were made in the laboratory portion of the AMTEX Partnership ${ }^{\text {Tw }}$ as a result of the funding profile for FY1997. DOE Defense Programs (DOE/DP), through the Office of Technology Partnerships (DP-17), is contributing \$10M for work at the national laboratories this fiscal year. DOE Energy Research (DOE/ER), which was the lead organization for AMTEX prior to FY 1997, is not participating in the program this year. These funding decisions were not finalized until late in the FY 1997 budget cycle. Changes resulting for this fiscal year include the following.

- The AMTEX Laboratory Program Office was moved from PNNL to the Oak Ridge Y-12 Plant. Dr. Mark Miller assumed laboratory program management responsibilities, replacing Dr. Doug Lemon, in November. The level of effort of the office will be less than in previous years due to budget constraints. In partial compensation for these reductions, the industry liaison office at Milliken and Company, directed by Mr. Stephen Freudenthal, has increased its support for the AMTEX program.

- The AMTEX research and development project portfolio for FY 1997 has been reduced to include only three projects; Demand Activated Manufacturing Architecture (DAMA), CAFE, and TReC. The Cotton Biotechnology and the On-Line Process Control projects have been put on hold because of budget considerations; these projects were being worked at DOE/ER laboratories.

- Because DOE/DP is the only funding office for FY 1997, the number of laboratories conducting AMTEX research and development activities has been reduced. Facilities active this year include LLNL, SNL, LANL, and ORNL/Y-12 Plant (OR/Y-12). In the latter case, ORNL will receive funding through the Y-12 Plant, a DP site, to allow continuation of CAFE project management and some $R \& D$ activities, as well as a part of the DAMA project.

- The formal AMTEX Partnership ${ }^{\text {tw }}$ report previously issued quarterly will now be issued semiannually, at the middle and end of the fiscal year. (This practice began in FY 1996). In addition, an abbreviated quarterly report will be generated for DOE/DP-17 at the end of the first and third quarters.

\section{Operating Committee Activities and Actions}

The AMTEX Operating Committee met on December 18, 1996 in Charlotte, North Carolina. The primary items of business were the status of AMTEX funding and progress reports on projects. Dr. Gerald Work, Chairman of the Operating Committee, led the general session.

Dr. Richard Quisenberry, Executive Director of AMTEX, talked about the current status of the Partnership mentioning that intellectual property is being transferred, hardware and software are being transferred, and deliverables are pretty much on schedule. He presented the financial history of AMTEX which showed industry contribution constant at about \$30M per year from 1995-1997, while DOE funds decreased from $\$ 26 \mathrm{M}$ to $\$ 16 \mathrm{M}$ to $\$ 10 \mathrm{M}$ in those three years. 
Dr. Quisenberry talked in general about promoting partnerships as a legitimate mechanism for both government and industry to meet their R\&D goals. The approach involves publicity, such as news articles in "Technology Transfer Business" and "New Technology Week" and reports from influential study groups such as the Council on Competitiveness, Center for Strategic and International Studies, and the National Research Council. In selling the partnership idea, the AMTEX principles are used as the example of the basis on which a successful public/private partnership should be established.

He then talked about building support for AMTEX specifically for the FY 1998 budget period and beyond. This involves securing sponsorship and support for AMTEX within DOE [wherever that may be-DP, ER, Energy Efficiency (EE)], understanding DOE's plans for AMTEX and supporting those plans as possible, finding Congressional support, and again, selling partnerships based on the AMTEX principles to Washington decision makers. The point was made that DOE is most interested in "mission-relevant" partnerships; economic competitiveness is no longer a DOE core mission.

The goal for FY 1998 is to restore the full R\&D agenda for AMTEX. This action would engage the entire range of the ITC, include DOE's ER and EM laboratories, involve the Environmental Protection Agency (EPA), and have the potential to attract participation from other government laboratories; Dr. Quisenberry estimated the budget needed for this agenda to be $\$ 25 \mathrm{M}$ from industry and $\$ 19 \mathrm{M}$ from government.

Industry project managers presented the status of their projects with emphasis on plans for work to be conducted in FY 1997. This information is included in the Projects Status Reports in a later section of this report.

Special presentations were made by Dr. Tom Malone to Dr. Work, Dr. Lemon, and Ms. Pat Ronaldson for their dedication and support for AMTEX over the years.

The next AMTEX Operating Committee meeting is scheduled for July 17, 1997, in Charlotte, North Carolina.

\section{Industry Technical Advisory Committee}

The Industry Technical Advisory Committee met on February 25, 1997, at the North Carolina State University College of Textiles in Raleigh, North Carolina. Dr. Quisenberry led discussions which focused on the budget, industry membership in AMTEX, and technical progress by the projects.

The FY 1998 budget submitted by the President to Congress has AMTEX as a line item in DOE/DP's budget at $\$ 5.5 \mathrm{M}$. In addition, DOE/ER is expected to contribute $\$ 3.5 \mathrm{M}$ in FY 1998. There is also the possibility is increasing the DP portion to \$10M. Dr. Quisenberry has responded to a request from the Senate Armed Services Committee for a four-year AMTEX budget. His submission shows \$13.5M in FY 1998 
(\$10M DP, \$3.5M ER), \$17M in FY 1999 (\$11M DP, \$6M ER), \$17M in FY 2000 (\$10M DP, \$7M ER), and \$11M for FY 2001 (\$6M DP, \$5M ER). AMTEX continues to champion the benefits of public/private partnerships in Washington. There appears to be a more positive response to this policy position than in the past few years.

On the subject of industry membership, Dr. Quisenberry noted that from FY 1996 to FY 1997 a number of partners were lost. Reasons for losing participation by individual companies include the annual funding uncertainties resulting from the federal budget process, suspended projects and tasks, and a perceived lack of commercial results. The first problem was most severe for FY 1997, when it was unclear as to whether AMTEX would receive any funding from DOE until after the start of the fiscal year. Suspension of the OPCon and BioCotton projects, and elimination of ER funds (and subsequently, ER laboratories) for $\mathrm{TReC}$ has resulted in loss of more than 30 participants. The DAMA and CAFE projects also lost several members each as budget reductions forced the original aggressive schedules for commercialization milestones to be moved back in time. Despite these problems, industry contributions continue to be greater than government contributions.

Industry project directors gave presentations of the status and expected FY 1997 results of their projects. Detailed project information is presented in the section "Project Status Reports."

Several observations were made about technical progress in general. (1) In some cases, too many initiatives have been started, it might be better to concentrate on one or just a few tasks that can be followed to completion. (2) While AMTEX is designed to work on generic, process- and system-related problems, commercialization requires that the results of the $R \& D$ be available as actual products for implementation by individual companies. This is the most difficult part of technology transfer and is the point where most of the projects find themselves. (3) The ability of potential vendors to capitalize the creation of products from new technology is as important as their technical ability. (4) It is almost impossible to move R\&D tasks from one laboratory to another and maintain continuity. (5) Industry must continually review and update their goals for projects and the specifications for hardware and software as projects progress.

The next Industry Technical Advisory Committee (ITAC) meeting is scheduled for July 9, 1997, in Charlotte, North Carolina.

\section{Miscellaneous}

Idaho National Engineering and Environmental Laboratory has opted to patent an invention, "Method of Colorant Removal," developed as a result of its work on the AMTEX TReC project. 

. 


\section{PROJECT STATUS REPORTS}

\section{Computer-Aided Fabric Evaluation}

The CAFE project is developing inspection systems that will provide U.S. textile manufacturers with a major leap forward in the assurance of high-quality, consistent textiles. The systems will allow real-time evaluation as cloth is made to ensure proper grading of fabric quality, reduction in running defects, and adherence to specification. In addition, machine diagnostics have been investigated that can be used as part of a predictive maintenance program to increase productivity in manufacturing plants.

$\begin{array}{lll}\text { Project Manager: } & \text { Glenn Allgood, ORNL } & \text { (423) } 574-5673 \\ \text { Project Director: } & \text { Mark Kametches, ITT } & \text { (864) 595-0035 }\end{array}$

\section{Project Administration}

Commercialization of CAFE technologies is the major thrust of FY 1997 work. Vendors are working with national laboratory researchers to define the specifications for hardware and software for commercial products implementing greige weave/knit and color printed pattern inspection systems.

The project is in the process of converting from individual CRADAs to one multilaboratory CRADA for the balance of the project scope of work. This will be the second AMTEX project to adopt a multi-laboratory CRADA.

A technical peer review of the project has been scheduled for June 18 and 19, 1997, at Oak Ridge. Reviewers include researchers from DOE laboratories, NTC universities, and industry.

\section{Machine Diagnostics Task}

Because of budget constraints, additional developmental work on the machine diagnostics system at ORNL will be discontinued. During the four-month beta test at a Burlington plant, which concluded early in fiscal 1997, the system successfully identified a major problem on one machine and process degradation on another. $A$ write-up of technical work to date will be completed this fiscal year. Project participants have been urged to pursue separate industry/laboratory arrangements outside of the CAFE project to put this technology to use. At this point, some preliminary discussions have been held but no firm plans for implementation have been made.

\section{Greige Weave/Knit Inspection Task}

Two test units of the SNL greige weave sensor system have operated at industry sites (Milliken and Glen Raven) for several months. These units have provided extensive data for the phenomenological studies necessary to improve the performance of the system. Noise glitch problems have been resolved that have reduced the false alarm rate to acceptable levels at one of the test sites. 
Full-width pick defect detection algorithms have achieved an acceptable rate of detection. Spot defect detection has improved. Synchronization of sensor sampling to fabric motion did not prove advantageous since at the sensor sampling rate the fabric velocity varies by at least a factor of seven. The warp defect detection rate is still below acceptable levels and current work has been redirected to concentrate on this problem. Industry is providing a more detailed definition of warp defect detection requirements.

A design modification to reduce the manufacturing cost of the system was suggested by the vendor, approved, and a prototype fabricated. The new design incorporates a detachable sensor head and separate electronics unit. On-sensor signal processing modifications have improved sensitivity and reduced drift and noise problems. SNL has worked with Y-12 and ORNL to ensure that control panels for the weave inspection device and the pick measurement device have the same look and feel for ease of use.

The knit inspection system leverages heavily off the weave inspection system for both hardware and software and will benefit from advances described above. Delivery of a prototype and documentation by the end of the fiscal year is on schedule.

Work on the pick measurement device (PMD, a linear diode array) at Y-12 and ORNL has been reduced in scope because of reduction in funding. A beta test device operated at a participant site for six months and performed within specifications for pick density on plain and twill weave fabrics. Conceptual design and requirements for the next generation device have been established, including modifications to reduce the cost of manufacture. Circuitry modification to filter interference from certain fabric types has been developed but funds are not available for field demonstration of this fix or design of software to allow automatic selection of filter adjustment for various fabric types. A delivery date of July 7 has been established for the next generation device as currently specified.

ATI Industrial Automation, the greige inspection systems vendor, has presented an economic analysis for commercial production of the weave/ $\mathrm{knit}$ inspection system and the pick measurement device. A range of manufacturing costs has been established for the greige weave system corresponding to the width of the machine and the number (density) of the sensors employed. One industry participant has expressed interest in near-term installation of a number of units. Cost for the PMD was evaluated on the basis of the first generation design. Modifications proposed for the second generation device should result in significantly reduced manufacturing cost through incorporation of formerly separate components into a one-piece design.

\section{Color Printed Pattern Task}

A vendor agreement was signed with two companies, Hunter and SheLyn, that will team in the commercialization of the color printed pattern inspection system being developed at SNL.

The conceptual system design for the beta test unit, which will allow inspection of cloth widths two and four times greater than that of the alpha test, has been completed on time. A schedule also has been determined to allow incorporation into the 
beta test unit of some pattern recognition algorithms and other information from the LLNL inspection system that was not selected for further work at the end of FY 1996.

Fieldcrest Cannon has been selected as industry participant for the beta test scheduled for September 1997. A week long pre-beta field test was conducted at the site during March 1997, allowing large quantities of data to be collected during normal production operations. This test used the original (alpha) computational platform for data acquisition and processing but incorporated a new lighting system, new camera lens, and an enhanced defect detection software routine. On-line classification of defects using the associated computer-aided design (CAD) file for the pattern was demonstrated in real-time at normal operating speeds. Optimal placement of the frame mark sensor and web encoder wheel were also determined. Defects were not intentionally introduced, as will be done during the beta test, so absolute values of detection and false alarm rate were not obtained.

Color Printed Pattern Goods (CPPG) team members visited Sara Lee Knitwear to observe print operations to identify potential differences between printing on knit versus woven material and to determine the feasibility and requirements for performing data collection at the site. There appears to be significant differences in fabric movement during the printing process of knit greige goods which might require additional processing by the inspection system software for defect detection. Plans are being made for data collection sometime late in FY 1997.

\section{Demand Activated Manufacturing Architecture}

The object of the DAMA project is to define, integrate, and demonstrate an electronic marketplace structure/system which can be used by all segments of the U.S. Integrated Textile Complex (fiber, textile, sewn products, and retail). The DAMA project will enable companies to reduce the lead time to fulfill requests for finished goods and establish new strategic alliances to create business opportunities. These steps will enhance industry productivity and competitiveness in the world marketplace.
Project Manager:
Leon Chapman, SNL
(505) $845-8668$

Project Director: Jim Lovejoy, [TC] ${ }^{2}$

(919) 3802184

\section{Project Administration}

For FY 1997 the DAMA project has undergone significant changes in the laboratory team with Lawrence Berkeley National Laboratory and Pacific Northwest National Laboratory leaving because of the lack of DOE/ER funds and LANL joining.

DAMA became the first AMTEX project to initiate a multi-laboratory CRADA as the legal vehicle for the project. Execution by all parties was finalized on March 24, 1997.

A peer review of the project was held in December. The review team consisted of persons from LANL, PNNL, SNL, ORNL, Georgia Tech, and Burlington Industries. The team noted that the national laboratory staff has demonstrated both technical competence and good technical performance. The degree of interaction and cooperation among the tasks and laboratories has improved to the level needed to achieve the goals of the overall program. Results to date have been at a high level and are 
not yet immediately useable by the industry. The team suggested that emphasis be placed on completion of tools and technologies that can demonstrate the benefits of DAMA concepts. The team also pointed out the need to increase the visibility of DAMA and establish more joint efforts with industry members.

The DAMA project office has issued the following documents:

FY 1997 Project Plan (final)

1996 (calendar year) Annual Report

DAMA Management Plan (version 1.2)

DAMA Architecture Status Report (version 1.0)

DAMA Peer Review (version 1.0)

\section{Enterprise Modeling and Simulation}

LANL, now heading the Enterprise Modeling and Simulation (EMSim) task, hosted a meeting of laboratory and industry participants involved in the pipeline analyses that will be performed this year to ensure consistency and quality of results. These analyses will be used to refine and test simulation and modeling tools that can identify new and modified business practices in the textile industry.

Five software programs were evaluated to assess their capability to support the pipeline analysis methodology. "Extend," a dynamic simulation code designed to handle discrete event models, has been chosen for prototype development of simulation models. The SCIP tool, developed by the CBM task, is being analyzed to see how it might be integrated into the suite of tools available for modeling and simulation of product pipelines. Analysis of the EMSim application developed earlier in the DAMA project has been terminated in favor of funding another TEXNET pilot by the Connectivity and Infrastructure (C\&I) task.

The Apparel Retail Modeling System (ARMS) tool, developed at North Carolina State University (NCSU) for retail sourcing simulation, has been enhanced and the user interface improved. The tool has been demonstrated at several industry sites and received very good reviews. It calculates the financial benefits to the retailer for various sourcing strategies.

The nylon jacket pipeline Phase I analysis report was issued and Phase II analysis initiated with development of a requirements document. The activity-based representation of the pipeline for the retailer (L.L. Bean) was completed. A template for data that will be needed for the model has been developed. The initial construction of the apparel manufacturing model has been completed. Development of a process technology database to support the model has also been initiated and personnel are working with NCSU and Institute of Textile Technology (ITT) in this effort. The team anticipates that approximately 200 process steps will be analyzed and included in the model.

The pipeline industry team for the Phase II analysis of the bedsheet pipeline has not yet been defined. One of the companies that participated in the Phase I analysis, Springs Industries, has dropped out of the DAMA project and a replacement has not been found. 
A third pipeline analysis, originally envisioned as a new product line investigation, has been changed to the development of a dynamic enterprise model simulation demonstration based on the men's cotton slacks pipeline. The model will be constructed along the same lines as the nylon jacket model but not to the same depth (approximately one third the number of process steps will be included). The model will be useful in visualizing the "as-is" operation of an entire pipeline and realistic, meaningful operations variations. The requirements document has been completed for this work. An Extend model of the major process steps has been prepared. Existing data have been incorporated into the simulation model and other necessary data have been collected and added. System metrics have been determined, and debugging of the model is underway. The demonstration simulation development is being coordinated with [TC $]^{2}$.

\section{Connectivity and Infrastructure}

Systems testing of TEXNET was successfully completed and a beta version installed at an industry participant's site. TEXNET is the only known example of a system that permits safe, secure transactions of sensitive information over the Internet. A sample trading partner agreement was published from the laboratory server to the industry user, who was able to execute the data request and retrieve data from the server. All of this was done with client authentication and full encryption of data over the network.

The first TEXNET pilot was initiated among Milliken, Warren Featherbone, and Mercantile. Hardware and software installations at the three sites and training of participating personnel were completed at the end of January and the system was operational on February 3, meeting a major milestone. Seven categories (e.g., inventory, product specification) and four formats (e.g., ASCII, SQL) of data are being shared among the companies. The pilot has been running successfully for two months and is scheduled to last through the fiscal year.

A second TEXNET pilot is being developed among L. L. Bean, Cone Mills, and Thomas Bradford (the latter is not a DAMA member). It is on schedule to begin operation in June 1997.

Briefings on TEXNET were presented at several DAMA partner sites and well received. Another briefing was given to the Comptroller of the Department of Defense and many of his high-level staff. C\&I personnel have also met with the TReC project Environmental Decision Tools task team to discuss the use of TEXNET as the infrastructure to allow sharing of environmental data among industry sites. Its use by $\mathrm{TReC}$ would constitute another pilot and demonstrate the flexibility of the system as well as the ability to install and run the system by personnel trained by the DAMA team.

The TEXNET development team released a major upgrade, TEXNET Version 2.0, at the end of March 1997. This software upgrade represents a significant improvement in performance, stability, and usability of the system. The new version will be installed at the companies participating in the first pilot in the near future and will be the version installed initially for the second pilot. 
be the version installed initially for the second pilot.

A report of the second "Electronic Data Interchange (EDI) over the Internet" pilot involving two industry participants has been released. Significant cost savings over Value Added Networks has been estimated for this type of data exchange.

Cooperative Business Management (CBM)

A batch update routine has been created for the National Sourcing Database (NSDB). Other routines have been created to allow back-up of the database and porting of files to different platforms. A stand-alone version of the NSDB has also been generated. Definition of necessary improvement in the cross data source searching capability has been made.

Discussions with the University of Southwestern Louisiana have been initiated to include the Louisiana Apparel Makers Database, maintained by USL, in the NSDB. An additional client command network utility must be written to access this remotely maintained database.

An updated SCIP requirement document and the draft technical design specification have been completed. The latter document describes the architecture, object model, analysis engine, event processor, and describes each non-graphical user interface class used in SCIP. It also includes several detailed test cases to use in testing the scheduling engine functionality.

Improvements have been made to the SCIP graphical user interface to allow more information to be obtained from the database rather than using fixed values. Scheduling routines were upgraded to perform more reliably and considerably faster. The object model has been enhanced to accommodate multiple manufacturing stages.

A software agreement signed between IBM and $[\mathrm{TC}]^{2}$ permits the use of certain IBMdeveloped tools as part of the SCIP analysis engine for development, demonstration, and piloting within the DAMA project, with participating DAMA member companies. Technical information exchanges have been initiated and the same test case has been run on SCIP and the IBM software to assess capabilities. Some redesign of the SCIP object model to allow interface and support of the IBM tool has begun.

DAME work has proceeded with creation of flow diagrams for textile, retail, apparel, and transportation logistics views of the model and associated dictionaries. Discussions with AAMA, who will take ownership of the apparel portion of DAME, have led to restructuring of the apparel view. The revised model has been sent to AAMA and ATMI for comment.

Presentations of the DAME methodology have also been made to two VICS committees: Logistics and Merchant Issues. Both committees have agreed to support efforts to model activities in their areas of interest, including Bill of Lading, and Forecasting and Planning. Other improvements designed and implemented for DAME involve a modified representation of EDI in the DAME model and the DAME dictionary and a world wide web (www) navigation diagram for the overall model. A prototype for the new www DAME presentation has been installed for review by the web page developer. 
A new CBM web site has been completed and is now available at http:// cbmnt1.energylan.sandia.gov, with a completely new look and feel. The CBM task plan, DAME, and SCIP content are included. The latter provides a pseudo webbased demonstration of SCIP with sample input and output screens.

\section{Education, Outreach and Commercialization (EOEC)}

DAMA exhibited at the Bobbin Show in October 1996. TEXNET, NSDB, DAME and SCIP were all demonstrated. A free-standing version of the latest NSDB was made available to all Associate Members of the American Apparel Manufacturers Association (AAMA), who hosts this conference.

DAMA exhibited at the ATMI conference in October 1996. DAMA tools were again demonstrated with the NSDB active through the Internet. This conference provides an excellent introduction to the small- and medium- sized enterprises which typically cannot afford to become research partners in AMTEX projects but are key to widespread acceptance and use of the technologies being developed by DAMA and other AMTEX projects.

Presentations were made at the AAMA Technical Advisory Committee meeting, the KTA annual meeting, and the Council of Logistics Management meeting. A DAMA poster session was presented at the National Textile Council Forum in January 1997. DAMA technologies will also be demonstrated at IQ 1997 in April.

Commercialization announcements were placed in the Commerce Business Daily for TEXNET and the NSDB. Expressions of interest were received from 26 companies. After telephone conversations with each to discuss the commercialization process, approximately half the respondents indicated further interest. A commercialization selection committee then solicited and reviewed business plans from prospective candidates. On February 12, 1997, six companies presented plans for commercialization of TEXNET and/or the NSDB before the committee.

IBM was selected as the vendor for TEXNET and will be granted a non-exclusive license to the technology by [TC] ${ }^{2}$. Discussions for how the technology will be made available to the industry are underway. Work is continuing with Internet Tradeline, Inc., the committee selection for commercialization of the NSDB. Both IBM and Internet Tradeline, Inc. (ITI) have joined the DAMA project as Research Affiliates.

The industry-led DAMA marketing plan committee has been formed to explore ways to increase awareness of and membership in DAMA. A draft marketing plan has been produced.

The EO\&C team has devised a metric to quantify success in broadening the base of participation of the U.S. ITC in electronic commerce. Called "Levels of Engagement," it is a graded series of increasingly sophisticated uses of DAMA tools and technologies. Starting with information requests about DAMA, it proceeds through use of e-mail to exchange of information on the Internet and finally to making business decisions via DAMA tools and true electronic commerce. DAMA has been successful at providing information to many of the thousands of textile companies, 
but at this time only a few companies have proceeded to the third or fourth level. The strategy of the EO\&C task is to grow this participation significantly as tools are developed, proven, and commercialized.

\section{Textile Resource Conservation}

The objective of the TReC project is to define, develop, integrate, and deliver processes, devices, and techniques to be used by all elements of the U.S. textile and soft goods product chain to enhance environmental quality and minimize the production of waste.

Project Manager:

Vacant

Project Director:

Don Alexander, ITT (864) 595-0035

\section{Project Management}

The $\mathrm{TReC}$ project has undergone a major reduction in scope with the absence of DOE/ER funding and, as a consequence, ER laboratories. The FY 1997 portfolio of projects includes one project at each of the DP laboratories- LLNL, LANL, and SNL. In addition, the laboratory project manager position, formerly held by Paul Farber at Argonne National Laboratory, has not been filled. By agreement, the project director will assume some of the duties of that position while others will be handled by the AMTEX laboratory program office.

There is no move to convert the individual CRADAs of this project to a single multilaboratory CRADA. The tasks comprising the TReC project are essentially independent of one another and, without a lead laboratory, there is no incentive to pursue a multi-laboratory CRADA.

\section{Emission Monitoring}

This task will be conducted at LANL. The goal of the task is to use a unique sensor technology developed at the laboratory to monitor specific air emission parameters, with the resulting data being used to modify production processes to reduce air emissions. If possible, the technology will be applied to aqueous effluents to allow individual production process monitoring as well as waste treatment monitoring.

The CRADA for this task was canceled at the end of last fiscal year, and the field prototype apparatus built in FY 1996 was disassembled and stored. In March 1997, documentation for a new CRADA was signed by all parties to allow work to begin for this fiscal year.

To date the field prototype has been cleaned, reassembled, calibrated, and diagnostic tasks run. The equipment appears to be in excellent working condition. A student research assistant has been recruited to help in the project.

\section{Environmental Decision Tools}

This task will be conducted at SNL. The goal of the Environmental Decision Tools (EDT) task is to develop and demonstrate an Internet-based information system that 
can access standardized environmental and manufacturing data from multiple industry sources while maintaining security of individual information. The system will be populated with selected environmental information and used to demonstrate how manufacturing process decisions and materials selection can be assessed for environmental factors by using commercially available tools. Analyses will be expanded in subsequent years to include economic considerations.

The existing CRADA for this task expired in November 1996. An amendment was prepared to extend the period of performance through FY 1997 and was approved by all parties in January 1997.

Discussions have been held between the TReC task leader and DAMA project personnel to explore the use of TEXNET as the system architecture for exchange of environmental data, leveraging off work already performed to create a secure information system. SNL personnel will be trained in the setup and operation of a TEXNET network and then train industry participants. This task will result in another pilot of TEXNET and an independent assessment of the ease of bringing the system on line with minimal designer consultation.

A contingency position has been developed in the event that not all of the participants in this task can purchase and install the hardware necessary to operate a TEXNET system this year. A commercial secure electronic mail package has been identified that will allow companies with $\mathrm{PC} /$ modem access to the Internet to become familiar with electronic security issues and experiment with various data formats, but without the more advanced features and ease of use afforded by TEXNET.

In parallel with the development of the architecture for data exchange, discussions have been held with industry representatives to understand the range of issues over which companies anticipate using environmental information. At the lowest level this involves data needed to meet compliance requirements. Participants have indicated that they also intend to use data for other purposes such as input to process modeling and life cycle analysis.

This initial understanding of data uses has allowed preliminary work on the data structures and templates to be developed for use with environmental databases to begin. $T \operatorname{ReC}$ personnel have also met with DAMA personnel working on the information flow and definition task to see if some other work already performed within DAMA could be useful to TReC.

\section{Enhanced Washing}

This task is being performed at LLNL. This promising technology has the potential to reduce the amount of water used in the textile industry for washing by a factor of four or five, saving millions of gallons of water per year if a commercially viable system can be developed.

Improvements have been made to the continuous washing apparatus that was constructed in FY 1996. A new separator material has proven to be more robust and provide better results than previous materials. Experimental results for tint removal 
from cotton twill fabric have resulted in cleaning enhancements through use of this technology of up to 27 times over simple rinsing. In another comparison, equivalent cleaning could be achieved at water use ratios of less than one third (i.e., $6 \mathrm{~kg}$ water/ $\mathrm{kg}$ fabric vs $20 \mathrm{~kg}$ water $/ \mathrm{kg}$ fabric) with the technology over simple rinsing.

Preliminary studies on the removal of caustic show that the process can be used for this purpose but cleaning efficiencies are not as good as those for tint removal. At relatively low levels of applied caustic ( 0.5 percent), a small but consistent (10 to 15 percent) improvement in caustic removal from a cotton/ polyester blend fabric was noted. The effect appeared to be largely independent of water use ratio.

At higher levels of caustic ( 5 percent), greater cleaning improvement was noted through use of the technology when cleaning cotton fabric. A 50/50 cotton/polyester showed less effect and 100 percent polyester essentially no effect at all. Based on these results, anticipated water savings are estimated at only 30 percent for cotton, which may not prove of economic interest. Additional tests are planned for chlorine and dye removal as well as mechanical enhancements to the system.

\section{Sensors for Agile Manufacturing}

This project was worked at Sandia but was not scheduled for funding in FY 1997. A small amount of carryover funding from FY 1996 was available for the last remaining milestone for the project-manufacture of a prototype felled seam sensor. SNL supplemented the carryover funds with about $\$ 40 \mathrm{~K}$ of reprogrammed FY 1997 funds that allowed the task to be completed and the device delivered to [TC] $]^{2}$.

\section{FINANCIAL SUMMARY}

Financial summaries for active projects are presented in the Appendix. 
Appendix

AMTEX Financial Information 
PROGRAM SUMMARY REPORT

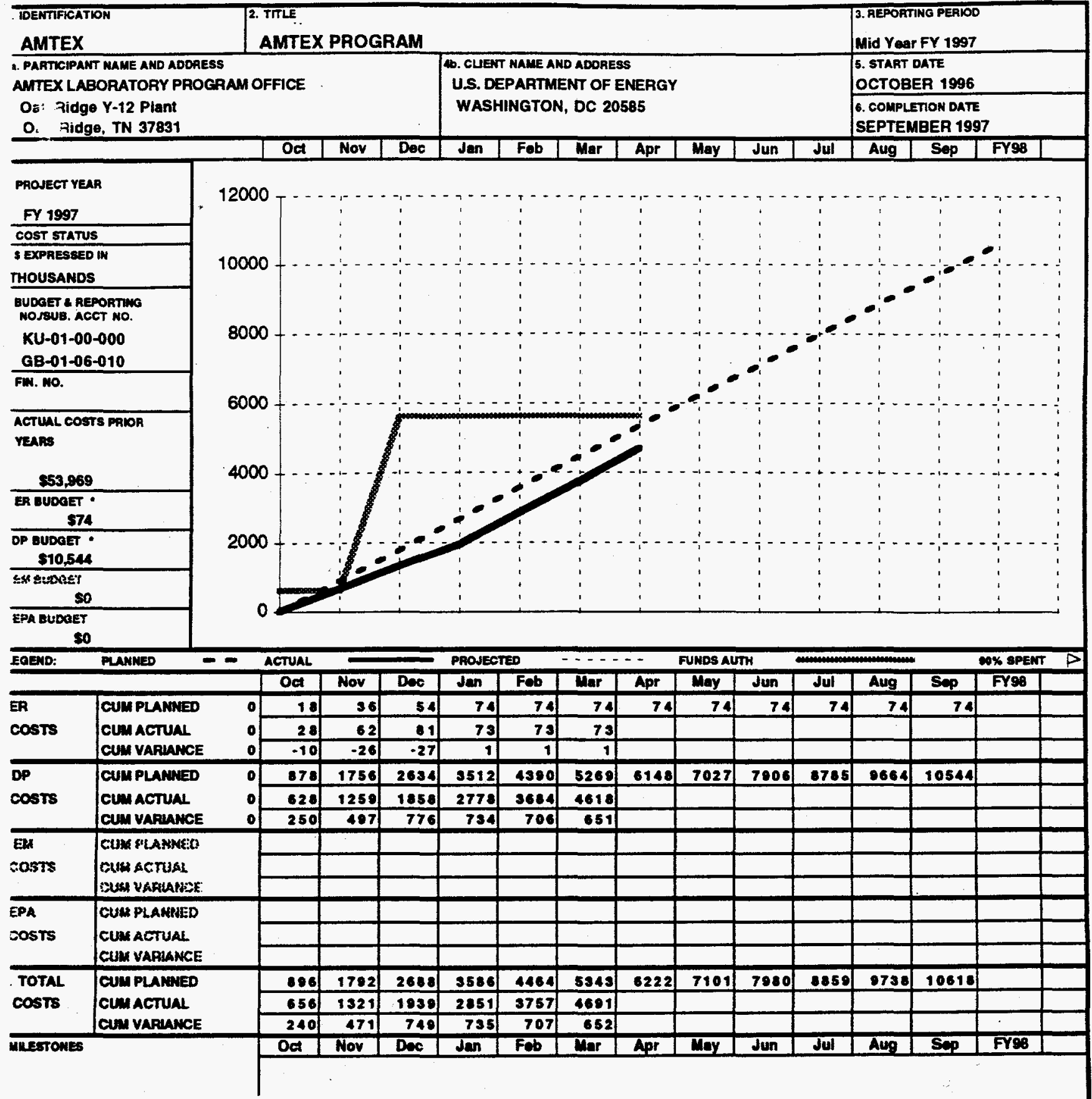

(REFER TO NOIVIOUAL PROJECT REPORTS)

UDELTS WCLUOE DP CARRYOVER FAOU FY 19HS OF SATOK, EA CARAYOYEA (CAFE ONLV OF 87 TK. 
PROJECT SUMMARY REPORT

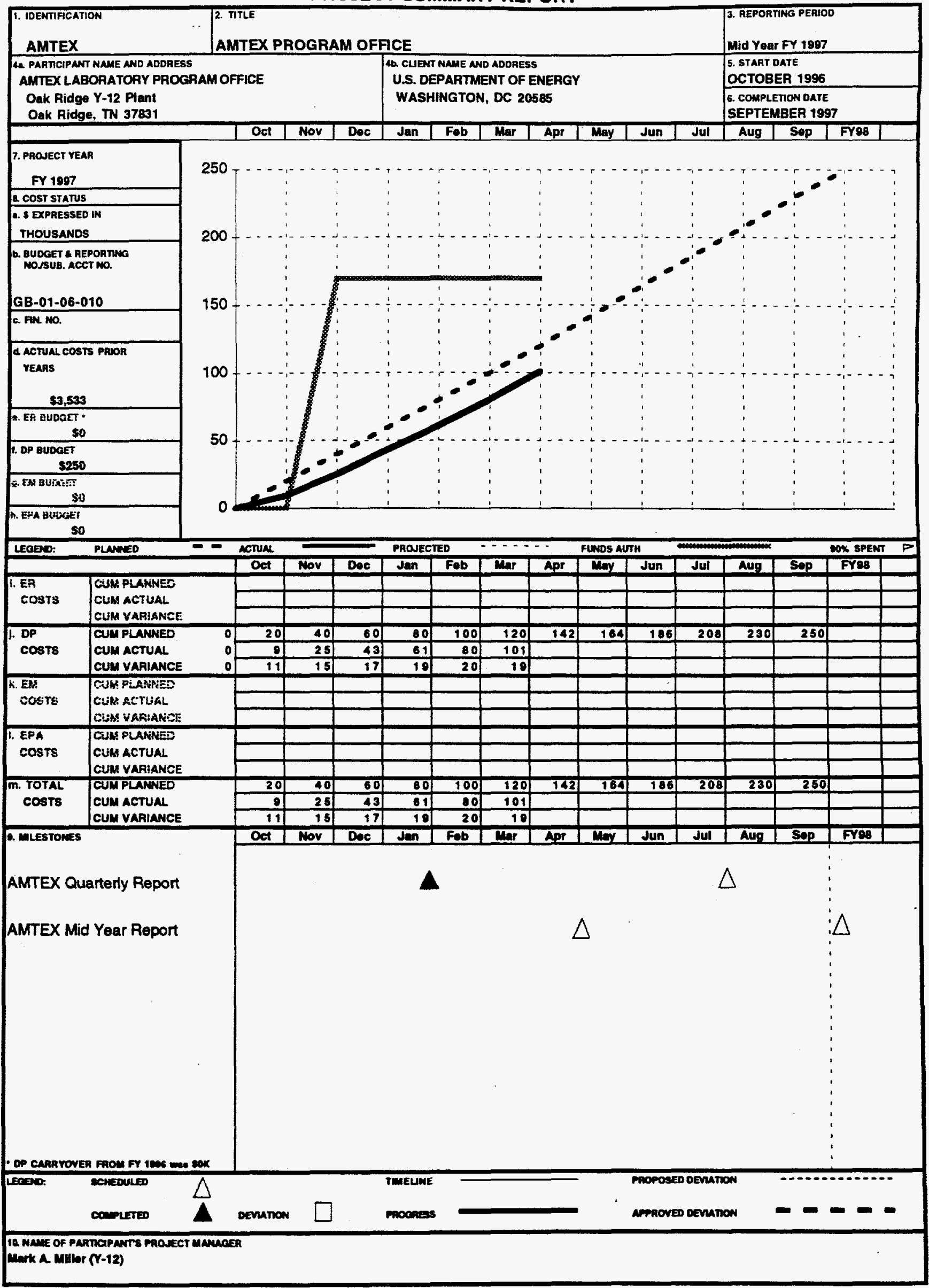


PROJECT SUMMARY REPORT

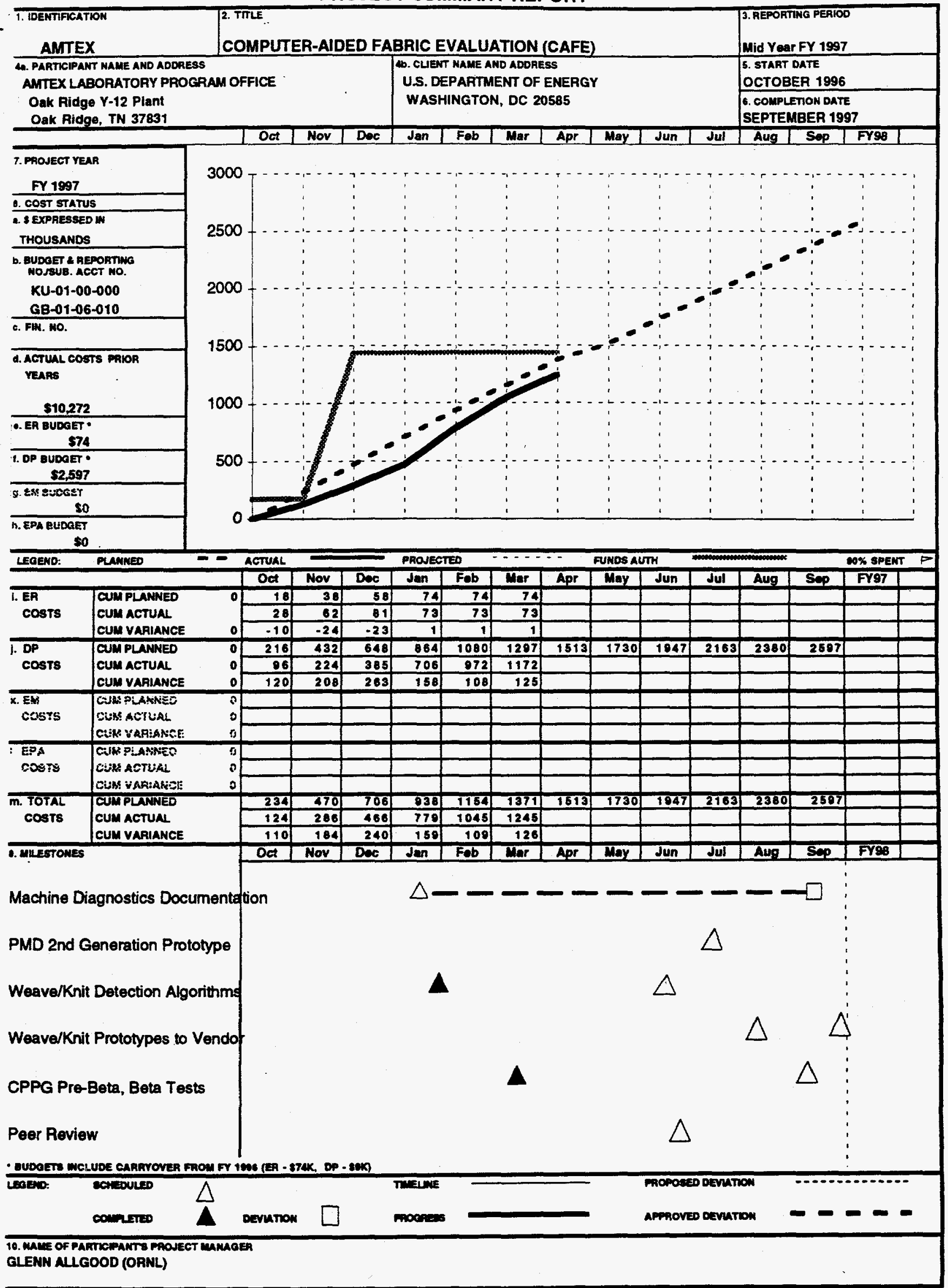


PROJECT SUMMARY REPORT

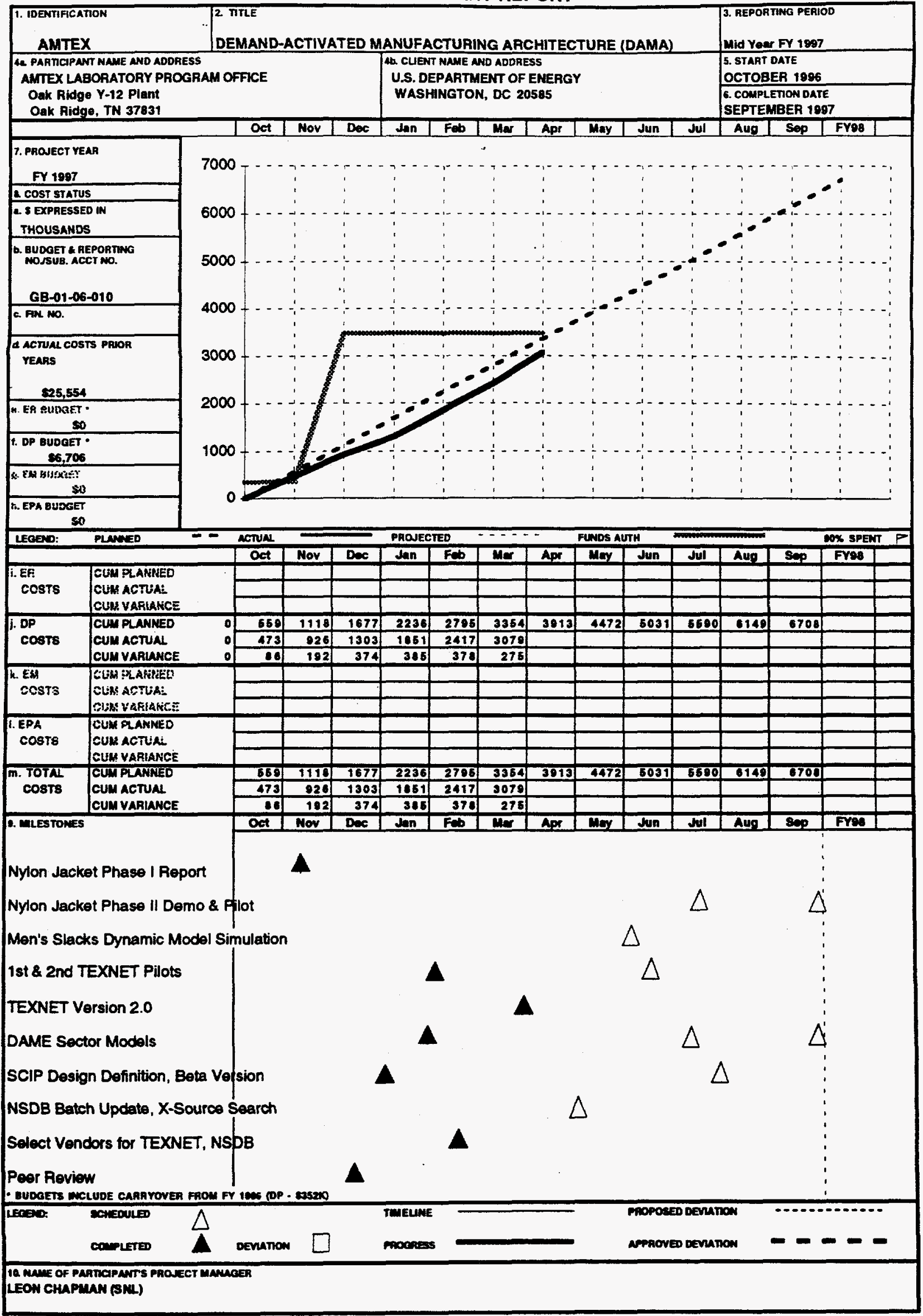




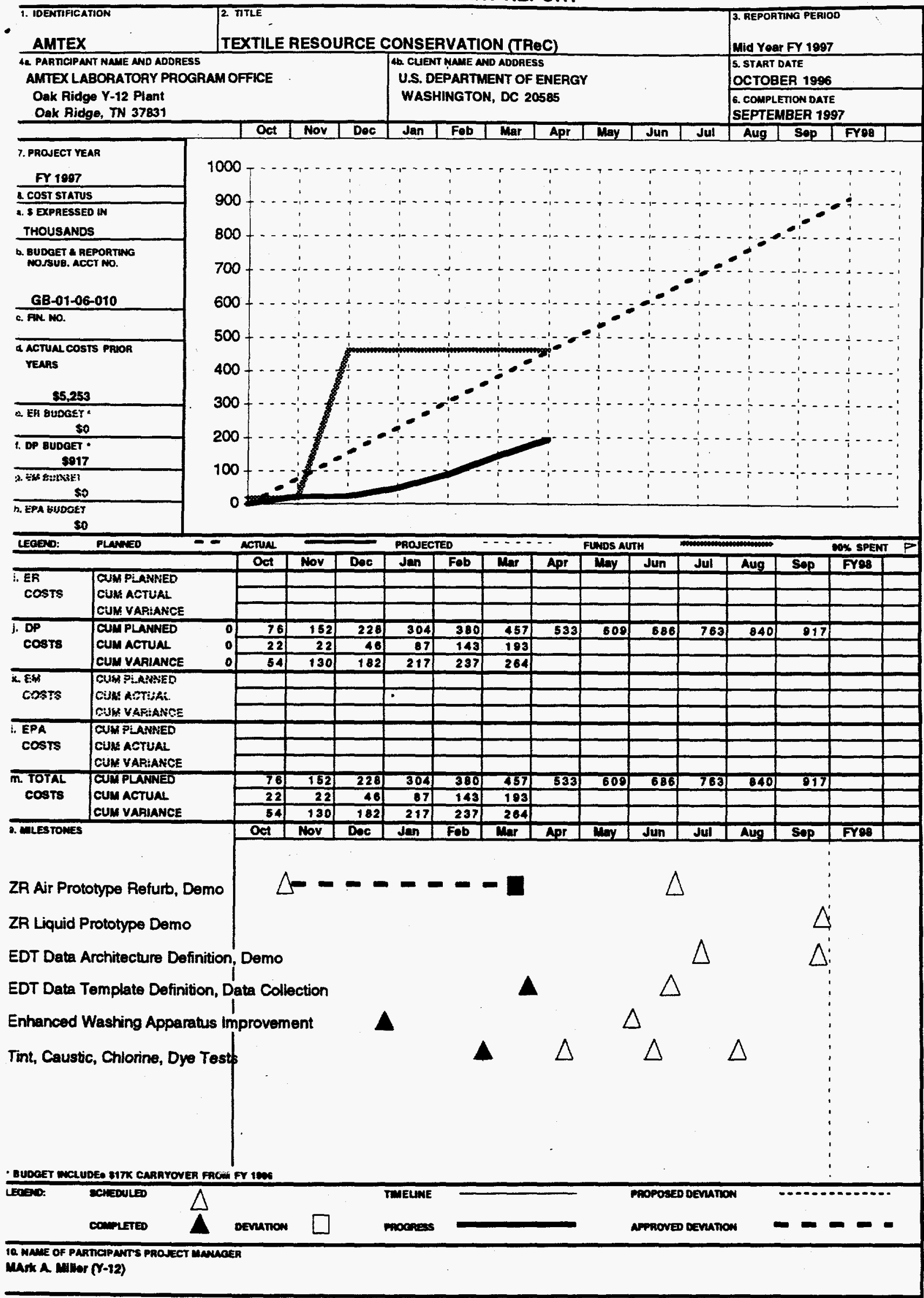




\section{DISTRIBUTION}

Internal (22)

G. O. Allgood

MS 6007

D. E. Beck

W. D. Brosey

J. L. Cook

W. W. Manges

D. W. McDonald

D. W. Mee

M. A. Miller (10)

R. C. Riepe

M. L. Simpson

R. S. Steele

J. W. Whittaker

Y-12 Central Files

External (131)

Fletcher Adamson, Corporate Vice President Machine Research \& Development

Russell Corporation

P.O. Box 272

Alexander City, AL 35010-0272

Don Alexander, TReC Project Director Institute of Textile Technology

Point West Office Bldg., Suite 203

775 Spartanburg Blvd.

Spartanburg, SC 29301

John Alexander

Idaho National Engineering

and Environmental Laboratory

P.O. Box 1625, MS: 3805

Idaho Falls, ID 83425-2214

Robert A. Barnhardt, Dean

College of Textiles

North Carolina State University

P.O. Box 8301

Raleigh, NC 27693-8301

Noelie Bertoniere

U.S. Department of Agriculture

P.O. Box 19687

New Orleans, LA 70179

Diane Bird, Director

Office of Technology Partnerships

U.S. Department of Energy / DP-17

1000 Independence Avenue SW

Washington, DC 20585

E. P. Blanchard, Jr.

P.O. Box $\mathbf{N}$

Kennett Square, PA 19348
Paul Braxton, Vice President

Textile Products Group

Cone Mills

3101 N. Elm Street

Greensboro, NC 27408

Ben Burr, Cotton Bio Project Manager

Brookhaven National Laboratory

53 Bell Avenue, Bldg. 463

Upton, NY 11973

Peter N. Butenhoff, President (10)

Textile/Clothing Technology Corporation [TC] ${ }^{2}$

211 Gregson Drive

Cary, NC 27511-7909

Randy Chang

U.S. Department of Energy

Oakland Operations Office

1301 Clay Street, 7th Floor

Oakland, CA 94612-5208

Leon Chapman, DAMA Project Manager

Sandia National Laboratory

P.O. Box 5800, MS: 0722

Albuquerque, NM 87185-0722

Helena Chum, Director

Renewable Chemical Tech/Materials Lab

National Renewable Engineering Lab

1617 Cole Boulevard

Golden, CO 80401-3393

Alan Claflin

Office of Computational / Tech Research

U.S. Department of Energy / ER-30

19901 Germantown Road

Germantown, MD 20874

Deborah Clayton

Technology Transfer

Argonne National Laboratory

9700 South Cass Avenue

Argonne, IL 60439

Jerry Cogan, Jr., President

Milliken Research Corp.

P.O. Box 1927

Spartanburg, SC 29304-1927

Harry Collins

Vice President of Research

Delta \& Pine Land Company

P.O. Box 157

Scott, MS 38772 
Fred L. Cook, Director

School of Textile \& Fiber Engineering

Georgia Institute of Technology

725 Atlantic Drive

Atlanta, GA 30332-0295

John Cooper

Lawrence Livermore National Lab

P.O. Box 808, MS: L-352

7000 East Avenue

Livermore, CA 94550

Joe D. Cunning, Director

National Textile Center

3640A Concord Pike, Room 201

Wilmington, DE 19803

George C. Dacey

3171 Laural Ridge Ct.

Bonita Springs, FL 34134

Pat Danahy, President \& CEO

Cone Mills

1201 Maple Street

Greensboro, NC 27405

James Davenport, Chair

Applied Science Department

Brookhaven National Laboratory

2 Center Street, Bldg. 179 A

Upton, NY 11973-5000

Thomas M. Duff, President

Fibers Division

Wellman, Inc.

1040 Broad Street, Suite 302

Shrewsbury, NJ 07702

Gall Eaton, Executive Director

Textile Research Institute

P.O. Box 625

Princeton, NJ 08542

Douglas Faulkner

U.S. Department of Energy

DOE-EE / FORSTL 5F-035

1000 Independence Avenue SW

Washington, DC 20585

Ritchie Fishburne, Director

Corporate Information Systems

Burlington Industries

P.O. Box 21207

Greensboro, NC 27410
James M. Fitzgibbons, Chairman \& CEO

Fieldcrest Cannon, Inc.

One Lake Circle Drive

Kannapolis, NC 28081

Ronald Foltz, VP Technology

Hoechst Celanese Corporation

P.O. Box 32414

Charlotte, NC 28232-9973

Craig Fong, Rapid Cutting Project Manager

Lawrence Berkeley National Laboratory

I Cyclotron Road, MS: 90-2148

Berkeley, CA 94720

Donald Foster, Technology Area Leader

Lawrence Berkeley National Laboratory

I Cyclotron Road, MS: 90-2148

Berkeley, CA 94720

Cheryl Fragiadakis

Lawrence Berkeley National Laboratory

One Cyclotron Road, MS: 90-1070

Berkeley, CA 94720

Jim Frede

Mercantile Stores Company, Inc.

9450 Seward Road

Fairfield, $\mathrm{OH}$ 45014-2230

Ken Freese, Manager

Technology Partnerships Program

Los Alamos National Laboratory

P.O. Box 1663, MS: C334

Los Alamos, NM 87545

Steve Freudenthal, Project Manager (5)

Milliken \& Company

P.O. Box 1926, M-149

Spartanburg, SC 29304

Mike Furey

Brookhaven National Laboratory

53 Bell Avenue, Bldg. 475

Upton, NY 11973

Allen Gant, Jr., President

Glen Raven Mills, Inc.

1831 North Park Ave.

Glen Raven, NC 27217

Roger Gilbertson

Program Manager for Basic Research

U.S. Department of Commerce

Mail Code Otexa-H3100

Washington, DC 20230 
J. Nicholas Hahn, President \& CEO

Cotton, Incorporated

- 1370 Avenue of the Americas

New York, NY 10019

William Hamlett

Fieldcrest Cannon

One Lake Circle Drive

Kannapolis, NC 28081

Michael Henderson, Director

Technology \& Safety Analysis Division

Los Alamos National Laboratory

P.O. Box 1663, MS: F606

Los Alamos, NM 87545

June M. Henton, Dean

School of Human Sciences

Auburn University / 210 Spidle Hall

Auburn, AL 36849

Gay Jividen, Cotton Bio Project Director

Cotton, Incorporated

4505 Creedmoor Road

Raleigh, NC 27612

Roger Johnston

Los Alamos National Laboratory

Bikini Atoll Road

P.O. Box 1663, MS: J565

Los Alamos, NM 87545

Mark Kametches, CAFE Project Director Institute of Textile Technology

Point West Office Bldg., Suite 203

775 Spartan Blvd.

Spartanburg, SC 29301

David Koegel

U.S. Department of Energy / ER-32

19901 Germantown Road

Germantown, MD 20874

Martha Krebs, Director

Office of Energy Research

U.S. Department of Energy, ER-1/7B-058

1000 Independence Avenue

Washington, DC 20585

Glenn W. Larsen, Executive VP

Manufacturing \& Operations

Biltwell Company, Inc.

2005 Walton Road

St. .Louis, MO 63114
H. Vernon Lemaster, President

Textile Products Group

Ciba-Geigy Corporation

P.O. Box 18300

Greensboro, NC 27419-8300

Douglas K. Lemon

Pacific Northwest National Laboratory

P.O. Box 999, MS: K8-21

Richland, WA 99352

Darryl Lindsey

Plains Cotton Cooperative Association

P.O. Box 2827

Lubbock, TX 79408-2827

Stuart Loken

Lawrence Berkeley National Laboratory

I Cyclotron Road, MS: 50B-4230

Berkeley, CA 94720

Jim Lovejoy, DAMA Project Director

Textile/Clothing Technology Corporation

211 Gregson Drive

Cary, NC 27511-7909

Roger Malkin, Chairman

Delta and Pine Land Company

One Cotton Row

P.O. Box 157

Scott, MS 38772

Thomas Malone, President \& COO

Milliken and Company

P.O. Box 1926, MS-149

Spartanburg, SC 29304

George Manthey

U.S. Department of Energy

Oak Ridge Operations Office

P.O. Box 2001

Oak Ridge, TN 37831

Kathleen McCaughey

Sandia National Laboratories

P.O. Box 5800, MS: 0507

Albuquerque, NM 87185-0507

Linda McCoy

U.S. Department of Energy

Idaho Operations Office

785 DOE Place

Idaho Falls, ID 83402

Dan McCreight, Vice President

Institute of Textile Technology

2551 Ivy Road

Charlottesville, VA 22903-4614 
Charles McKeller, Vice President

Glen Raven Mills, Inc.

1831 North Park Ave.

Glen Raven, NC 27217

Lewis Meixler, Director

Office of Technology Transfer

Princeton Plasma Physics Laboratory

P.O. Box 451

Princeton, NJ 98543

Roger Milliken, Chairman \& CEO

Milliken and Company

234 S. Fairview Ave.

Spartanburg, SC 29302

Michael Mishoe

Office of Technology Partnerships

U.S. Department of Energy /DP-17

1000 Independence Avenue SW

Washington, DC 20585

David Nelson

Office of Energy Research

U.S. Department of Energy / ER-30

1000 Independence Avenue

Washington, DC 20585

David L. Nichols, Chairman \& CEO

Mercantile Stores Company, Inc.

9450 Seward Road

Fairfield, OH 45014-2230

Angela Padilla

U.S. Department of Energy

Albuquerque Operations Office

P.O. Box 5400

Albuquerque, NM 87185-5400

Patty Padilla

U.S. Department of Energy

Albuquerque Operations Office

P.O. Box 5400

Albuquerque, NM 87185-5400

Lucien Papouchado

Savannah River Technology Center

P.O. Box 616

Aiken, SC 29802

Homi B. Patel, President

Hartmarx Corporation

101 N. Wacker Drive, 23rd Floor

Chicago, IL 60606
Pete Pesenti, Sr. Research Engineer

U.S. Department of Energy / ER-32

19901 Germantown Road

Germantown, MD 20874

Norman D. Peterson, Special Assistant

Strategic Planning Group

Argonne National Laboratory

9700 South Cass Ave. / OTD

Argonne, IL 60439

Charles Pietri

U.S. Department of Energy

Chicago Area Office

9800 South Cass Avenue

Argonne, IL 60439

Richard Quisenberry, Executive Director (20)

AMTEX Program Office

P.O. Box 4670

Wilmington, DE 19807

David Rae, Vice President

Nylon Technology

E.I. du Pont de Nemours \& Co.

P.O. Box 88025

Wilmington, DE 19807

John Renfro, Jr., Vice President

Inman Mills

P.O. Box 207

Imnan, SC 29349

Victor Reis, Assistant Secretary for Defense Programs

U.S. Department of Energy /DP-1

1000 Independence Avenue

Washington, DC 20585

Mike Riley, EEF Project Manager

Lawrence Livermore National Laboratory

7000 East Ave., L-39

Livermore, CA 94583

Douglas V. Rippy, Director

School of Textiles

Clemson University

Clemson, SC 29631

Art Roth, President

Cookson Fibers, Inc.

P.O. Box 8930

Bristol, VA 24203

Burton B. Ruby, Chairman

Trans-Apparel Group

5000 S. Ohio Street

Michigan City, IN 46360 
Virgil Sanders

- Los Alamos National Laboratory

P.O. Box 1663, MS: J567

Los Alamos, NM 87545

Preston E. Sasser, Sr., Vice President and Managing Director of Research

Cotton, Incorporated 4505 Creedmoor Rd.

Raleigh, NC 27612

Norm Sather, Director

Energy Systems Division

Argonne National Laboratory

9700 South Cass Avenue

Argonne, IL 60439

Nancy Saxer

Office of Technology Transfer

Lawrence Berkeley National Laboratory

1 Cyclotron Road, MS: 90-1070

Berkeley, CA 94720

Subhas Sikdar, Director

Sustainable Technology Division

U.S. Environmental Protection Agency

26 W. Martin Luther King Dr., MS: 4-97

Cincinnati, $\mathrm{OH} 45268$

Irving Stowers

Science \& Technology Advisor

Lawrence Livermore National Laboratory

P.O. Box 808, MS: L-644

Livermore, CA 94551

John Sullivan, Vice President

Business Development

Hoechst Celanese Corp.

P.O. Box 32414

Charlotte, NC 28232

William Toth

Idaho National Engineering

and Environmental Laboratory

P.O. Box 1625, MS: 2214

Idaho Falls, ID 83415-2214

James Van Fleet

U.S. Department of Energy / DP-10

1000 Independence Avenue SW

Washington, DC 20585

Brian Volintine

U.S. Department of Energy / EE-22

1000 Independence Ave SW

Washington, DC 20585
George Waldrep

Corporate Group Vice President

Burlington Industries

P.O. Box 21207

Greensboro, NC 27420

William K. Walsh, Head

Textile Engineering Department

101 Textile Building

Auburn University

Auburn, AL 36830

Ted Waroblak, President (5)

Institute of Textile Technology

2551 Ivy Road

Charlottesville, VA 22903-4614

Ted Wheelis

Sandia National Laboratories

P.O. Box 5800, MS: 0730

Albuquerque, NM 87185-0730

Gerald L. Work, Chairman

AMTEX Operating Committee

Pacific Northwest National Laboratory

P.O. Box 999, MS: K1-40

Richland, WA 99352 